\title{
Capital investment
}

\section{Funding schemes are set to promote the transfer of lab research into marketable technology.}

The pages of Nature Physics are filled with research that is fundamental in character. The translation of this progress in the understanding of physics into marketable applications is rarely straightforward. The route from basic experiment to industrial process may be long and tortuous, and once-valuable linkages have been eroded: the closure of Bell Labs, for instance; the current economic climate discouraging companies from investing in more speculative research that may not obviously bring a prompt return.

This issue of transfer is now being tackled in two areas of research that feature regularly in Nature Physics: quantum physics and graphene. Quantum Wave Fund (or Qwave) is a venture capital firm, operating out of Boston, New York and Moscow, that will offer funding for the transfer of researchers' progress in quantum technologies into the commercial sector (http://go.nature.com/QMLSts). At the end of 2012, Qwave announced that it had raised $\$ 30$ million of its $\$ 100$ million target, and had established a team of physicists, computer scientists and science and management experts who will lead its efforts to take quantum technology - for data transmission, accurate measurement, or optical transistors - from the lab to the market.

An even bolder vision for the exploitation of basic research is encapsulated in the European Union's Future and Emerging Technologies 'flagship' programme. Six projects are on the shortlist, having each already been awarded $€ 1.5$ million to conduct one-year feasibility studies (K. Kupferschmidt, Science 339, 28-29; 2013). The European Commission is set to announce two winners as Nature Physics goes to press, and the stakes are almost unimaginably high: the chosen two will receive funding to the tune of $€ 1$ billion over ten years.

One of the shortlisted projects pertains to research on graphene, the supermaterial that may, or may not, become the basis of future 'disruptive' technology. The first sample of graphene was made at the University of Manchester in 2004, by Andre Geim and Konstantin Novoselov, who then shared the Nobel Prize in 2010. Another year later, in October 2011, UK Chancellor George Osborne announced a $£ 50$ million investment in developing graphene and its spin-off technologies, intended, he said, to "take this Nobel-Prize-winning discovery from the British laboratory to the British factory floor." The National Graphene Institute is set to open in Manchester in 2015.

But the UK is lagging in its efforts to capitalize on a discovery made within its borders. A recently released analysis of patents related to graphene suggests that other nations have been much quicker to react and invest (http://go.nature.com/EXO1rk). China leads the field with by far the most patents filed $(2,204)$, followed by the USA $(1,754)$ and South Korea $(1,160)$. The UK has so far claimed only 54 patents.

The coordinated effort (across about 120 research groups) and substantial funding of the EU flagship programme could well be what Europe (and the UK within Europe) needs, if Asia and the USA are to be challenged for the lead on graphene research. Concerns have rightly been raised over whether $€ 1$ billion will really be forthcoming from cash-strapped European nations, over the efficacy and responsiveness of a large bureaucratic project - and of course over the prospects of graphene really fulfilling promises of being 'the new silicon'. But, if graphene makes it past the post for flagship funding, the EU could well be backing a winner.

\section{App-y days}

\section{Nature Physics is now available in an iPad app.}

Physicists tend to be gadget fans, quick to adapt to new technologies. If you're reading this on an iPad, you may be pleased to learn that Nature Physics is one of a group of Nature journals now available in the NatureJournals app, which is free to download from the App Store.

There's been an iPad version of Nature since 2011, but the new app (for iPads using iOS 5 or above) enables easy issue-by-issue browsing through tables of content (pictured). Other features include sharing, bookmarking (and synchronization of bookmarks across devices), saved searches, variable font size, a figure-viewing panel plus zoom on figures and images, active links for references, downloading of PDF versions of articles and downloading for offline access to the journal.

If you're a personal subscriber to Nature Physics, then you already have access to the content on the app. If you're not a subscriber, a preview issue is available for free, and you can choose to buy only the iPad version of the journal (pricing details are available here: www.nature.com/mobile/ naturejournals/index.html). For readers who usually access Nature Physics through their institution's online-only site licence, we expect iPad-version access to be available by the middle of 2013.

Nature Communications and our open-access title Scientific Reports are also included in the app - alongside Nature, whose journalistic content can be downloaded free of charge. More Nature journals in the physical sciences will join later in the year.

Do explore the app and give us your feedback: get in touch at mobile@nature.com.

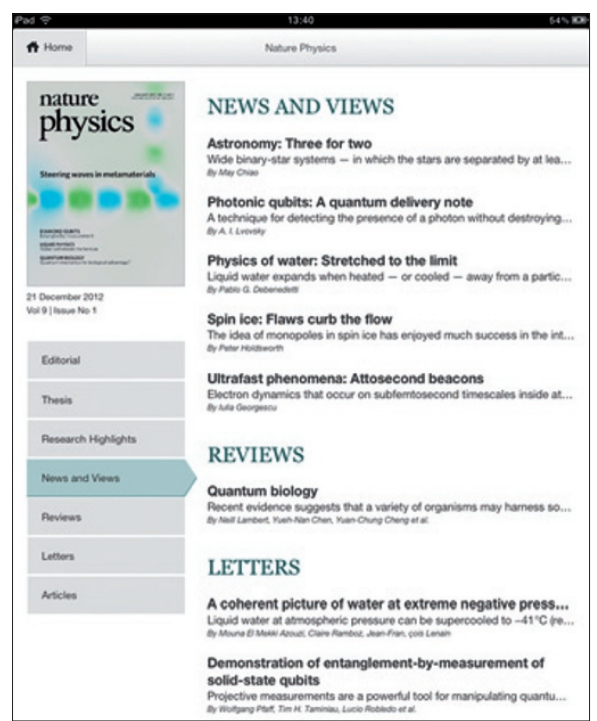

